\title{
Analysis of the surface microtextures and morphologies of beach quartz grains in Japan and implications for provenance research
}

\author{
Hiromi Itamiya ${ }^{1,2^{*}}$, Ritsuko Sugita ${ }^{1}$ and Toshihiko Sugai ${ }^{2}$
}

\begin{abstract}
The mineral quartz is highly resistant to weathering, and various surface microtextures are formed and preserved on quartz grains. These microtextures are considered to reflect the sedimentary history of quartz: parent rock, transportation process, and depositional environment. Thus, quartz grain surface textures have been widely studied for applications in provenance research. This study focuses on beach sediments in Japan that contain various quartz morphologies resulting from the region's complex geological and geomorphological settings. The goal of the study was to verify the morphological diversity of these quartz grains and reveal the relationship between the quartz morphological features and the sampling site in tectonically active regions. We collected beach sands from backshores in Japan and observed the 15 microtextures of the quartz surfaces using scanning electron microscopy (SEM). The shapes of the quartz grains were also evaluated in terms of roundness parameters based on SEM images. Finally, the particle size distribution and mineral composition of the samples were investigated. The results indicate that quartz roundness can accurately reflect the quartz grain shape and shows a good correlation with the outline observed by SEM. Mechanical features were more frequently observed on the surface of quartz than chemical features. Results show that the coastal areas were under high-energy beach. The coastal sand quartz grains are mainly characterized by (i) v-shaped percussion cracks produced by grain-to-grain collisions in the subaqueous environment and (ii) small holes derived from small inclusion remnants. The v-shaped percussion cracks are related to the sediment source (e.g., a fluvial or marine source), and the holes on the surface are related to the geologic source of the quartz grains. The grain size and mineral composition results support the results of the surface analysis and provide clues regarding sediment provenance. Quartz surface analysis has the potential to show the morphological variation of the coastal sand and provide useful information on the transportation process and parent rock even in areas with complex geological and geomorphological settings such as Japan. The relation between the quartz morphological features and sampling site was based on previous study; however, to develop the analysis, the relation between unweathered quartz shape and parent rock must be clear.
\end{abstract}

Keywords: Quartz microtextural analysis, Provenance research, SEM, Inclusion, Grain roundness, Coastal sand

\footnotetext{
* Correspondence: hiromii@nrips.go.jp

'National Research Institute of Police Science, 6-3-1 Kashiwanoha, Kashiwa,

Chiba 277-0882, Japan

${ }^{2}$ The University of Tokyo, 5-1-5 Kashiwanoha, Kashiwa, Chiba 277-8563, Japan
} 


\section{Introduction}

Quartz, a common rock-forming mineral, is highly resistant to weathering (Goldich 1938). Transportation and deposition processes cause numerous microtextures to be formed and preserved on the surfaces of quartz grains (Margolis and Kennett 1971; Krinsley and Doornkamp 1973). Thus, the microtexture of a quartz surface (MQS) reflects the sedimentary history of the quartz grain: its parent rock, transportation process, and depositional environment. MQS has been extensively studied using scanning electron microscopy (SEM), and the relationship between MQS and sedimentary history has been investigated (e.g., Krinsley and Doornkamp 1973; Le Ribault 1977; Mahaney 2002). The effectiveness of the MQS analysis has been demonstrated in provenance studies focused on, for example, tsunami and storm deposits (Costa et al. 2012, 2018; Bellanova et al. 2016), tsunami modeling (Mahaney and Dohm 2011), in situ and eolian origins (Newsome and Ladd 1999), and frost weathering and glacial grinding (Woronko 2016).

In Japan, the relation between morphological features of quartz and its sedimentary history may be different from that detailed in a previous study regarding landmass. Japan is an island arc located in an active continental margin that is one of the most tectonically active regions in the world (Moreno et al. 2016). Japan's complex landmass comprises numerous rock types, including plutonic, volcanic, and metamorphic rocks. Geomorphologically, the Japanese Islands are 59\% mountains, 6\% volcanoes, and $35 \%$ hills and coastal lowlands (Yonekura 2001). Japan is prone to rainfall-induced shallow landslides as a result of its high-relief topography and heavy rainfall during the East Asian summer monsoon season (Saito et al. 2010). This unique combination of geomorphological and climatic features results in rapid geomorphological changes in Japan (Oguchi et al. 2001). For these reasons, the Japanese Islands possess various source rock types, along with distinctive conditions for sediment transport and deposition. Therefore, various types of MQS may be observed reflecting complex landmasses, and MQS analysis can provide in-depth information about sedimentary history to contribute to provenance research. In Japan, however, only a few studies have estimated sediment provenance based on a variation in MQS (Mii and Fuji 1970; Okubo and Monodane 1974). Other researches have estimated fault activity using not MQS types but quartz surface relief (Kanaori et al. 1980, 1985, 1991; Niwa et al. 2016). It is necessary to gain fresh insight regarding morphological diversity of quartz and its relationship with sedimentary history to facilitate provenance studies of tectonically active regions.

In this study, we evaluated the morphologies and surface microtextures of quartz grains from beach sediments in
Japan with the goals of (1) verifying the morphological diversity of quartz grains in Japan and (2) revealing the relationship between quartz morphological features and the geomorphological and/or geological settings of sediment deposition. Beach sands were collected from 18 sites characterized by different sediment sources and transport processes. Among the 18 sites, nine were located in close proximity along the sandy coastline to evaluate the morphological diversity of quartz grains across this area.

\section{Geological setting}

Figure 1a provides a map of the sampling sites, and the geological maps of the different sampling areas are shown in Fig. 1b-f. The map in Fig. 1a was revised based on a digital map (Map Image) called GSI Map (Geospatial Information Authority of Japan 2013), and the geological maps (Fig. 1b-f) were revised based on the geological map of Japan (Geological Survey of Japan, National Institute of Advanced Industrial Science and Technology 2015). The tectonic lines shown in Fig. 1c, f are taken from the tectonic summary map (Moreno et al. 2016).

\section{Area I}

Area I is located in Shimokita Peninsula, Aomori Prefecture (Fig. 1b). The eastern coastline of area I faces the Pacific Ocean, and the western line faces toward Mutsu Bay. Towada volcano, which is located to the southwest of the sampling sites, erupted at the rate of once every 1000 and 2000 years over the past 10,000 years (Hayakawa 1985) and spread some volcanic ash to the northeast, east, and southeast (Machida and Arai 2003). Towada volcano and the surrounding area are covered with basaltic andesite to rhyodacite with phenocrysts of plagioclase, augite, hypersthene, magnetite, and occasional olivine (Hayakawa 1985; Machida and Arai 2003). This area also includes moderately sized hills covered with volcanic and pyroclastic rocks (Pleistocene to Holocene), along with a few rivers with lengths up to $140 \mathrm{~km}$ near the sampling sites. The geological setting of the sampling site is sedimentary rock (Pleistocene to Holocene) (Tsushima 1964; Kamada et al. 1991).

\section{Area II}

Area II is located in Niigata and Toyama Prefectures (Fig. 1c). The coastline of this area faces the Sea of Japan, and the southern part of area II contains a large mountainous area with an elevation of over $3000 \mathrm{~m}$, known as the "Japanese Alps." Steep rivers flow over plains from the Japanese Alps to the Sea of Japan [e.g., the average river slope of the Hime River is 1/80 (Handa et al. 2013)]. The water levels of these rivers are increased by meltwater from the Japanese Alps in the 


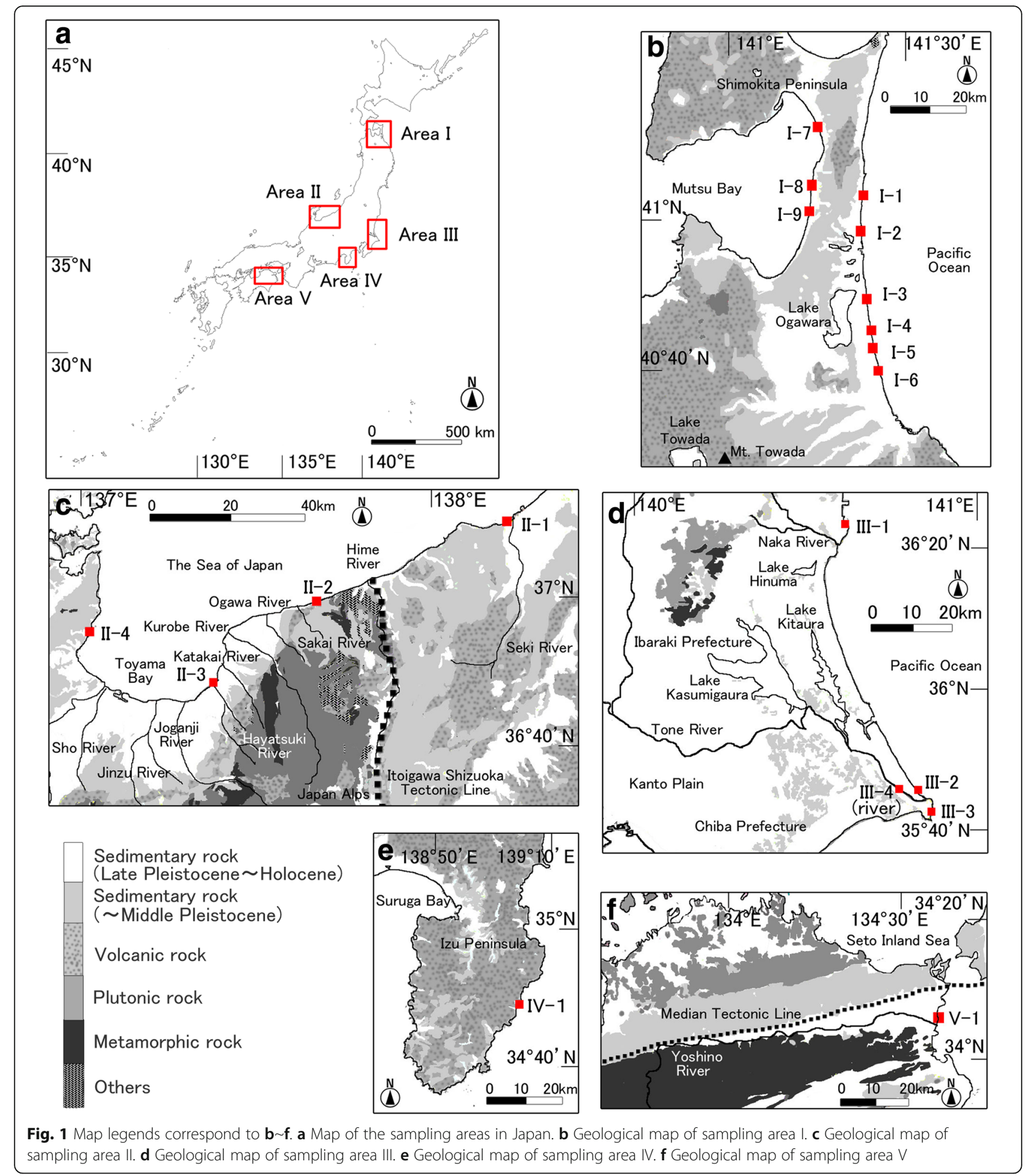

snowmelt season (Fukuda 1939; Fukuda and Sekiguchi 1940). The geological settings of the river basins are complex, and various sediment types such as igneous, sedimentary, and metamorphic rocks cover the area (Sakamoto et al. 1967; Yamada et al. 1989; Takeuchi et al. 1994; Harayama et al. 1996). The Itoigawa-Shizuoka
Tectonic Line (ISTL) runs from north to south along the Hime River valley. The eastern side of the ISTL is dominated by sedimentary and volcanic rocks, whereas plutonic and metamorphic rocks cover the western side (Sakamoto et al. 1967; Yamada et al. 1989; Harayama et al. 1996). 


\section{Area III}

Area III is located in Ibaraki and Chiba Prefectures (Fig. 1d) within the Kanto plain. The eastern coastline is a sandy beach that faces the Pacific Ocean. The Naka River has a length of $150 \mathrm{~km}$ and is covered with Quaternary volcanic at upper reach, Paleozoic sediments at middle reach, and Quaternary strata at lower reach (Yamamoto et al. 2000; Yoshioka et al. 2001). The Tone River, which is the second longest river in Japan, has a length of $322 \mathrm{~km}$. The Tone River flows from the mountainous area, which is primarily covered with Cenozoic volcanic and Mesozoic sedimentary rocks, and then through the alluvial plain (Sudo et al. 1991). The Kanto plain is filled with Neogene-Quaternary sediments (Unosawa et al. 1983; Yoshioka et al. 2001).

\section{Area IV}

Area IV is located in Izu Peninsula, Shizuoka Prefecture (Fig. 1e). The elevation of the peninsula is less than $1500 \mathrm{~m}$. This area contains no long rivers and is widely covered with Neogene to Quaternary volcanic rocks (e.g., andesite and basalt) (Sugiyama et al. 2010; Takeuchi et al. 2015). Narrow beaches with widths of several tens of meters are developed along the peninsula, as indicated by the GSI Map (Geospatial Information Authority of Japan 2013).

\section{Area V}

Area $\mathrm{V}$ is located on the island of Shikoku in Tokushima Prefecture (Fig. 1f). The Yoshino River, which has a length of $194 \mathrm{~km}$ and flows near the Median Tectonic Line, supplied the beach sediments around the sampling site (Mitsui et al. 1979). The northern side of the river course is covered with sedimentary rock, whereas the southern side is covered with regional metamorphic rock (e.g., green schist) (Isomi 1959; Makimoto et al. 1995; Matsuura et al. 2002).

\section{Methods/Experimental}

Several hundred grams of beach sand were collected from the surface of the backshore at each of the 18 sites in areas I to V (Fig. 1): nine samples from area I (Aomori), four samples from area II (Niigata and Toyama), three samples from area III (Ibaraki and Chiba), one sample from area IV (Shizuoka), and one sample from area V (Tokushima). Beach sands at sandy coast were collected from a few meters upper from shoreline at full flood during March August (Spring Summer).

Among the nine samples collected from area I (Aomori), six samples (I-1 to I-6) were taken from the beach facing the Pacific Ocean, and the remaining three (I-7 to I-9) were collected from the beach facing Mutsu Bay. The area I samples were used to detect the morphological diversity of quartz grains across the area. In area
II (Niigata and Toyama), three samples were collected near river mouths: $0.3 \mathrm{~km}$ west of the Seki River (II-1, Niigata), $6 \mathrm{~km}$ west of the Sakai River (II-2, Niigata), and $3 \mathrm{~km}$ north of the Hayatsuki River (II-3, Toyama). The fourth sample (II-4, Toyama) was collected $20 \mathrm{~km}$ from the adjacent major river mouth of the Oyabe River. Samples II-1 and II-3 were collected from river plains, whereas II-2 and II-4 were taken from beaches facing the hill. In area III (Ibaraki and Chiba), three samples were collected near river mouths: $6 \mathrm{~km}$ north of the Naka River on a pocket beach (III-1, Ibaraki), $2 \mathrm{~km}$ north of the Tone River (III-2, Ibaraki), and $4 \mathrm{~km}$ south of the Tone River on a pocket beach (III-3, Chiba). As a reference, fluvial sediment from Tone River was collected at III-4 and was analyzed without mineral composition. In area IV (Shizuoka), IV-1 was collected from a sandy beach located behind the hill. In area $\mathrm{V}$ (Tokushima), V-1 was collected $0.3 \mathrm{~km}$ north of the mouth of the Yoshino River. In this study, we call "area I" as area name, "site I-1" as sampling site name, and "I-1" as sample name.

\section{Analysis of grain size and mineral composition}

Particle size distribution was measured using a laser diffraction particle size analyzer (Shimadzu, SALD-3000S), and the mineral composition of each sample was determined using a stereomicroscope. For each sample except fluvial sediment III-4, over 500 sand particles with sizes in ranging from 0.1 to $1 \mathrm{~mm}$ were observed and classified into four groups with reference to the method of Ishii (Ishii et al. 2009): "colored minerals," "magnetic minerals," "colorless minerals," and "rock fragments and others."

\section{Analysis of quartz shape and surface}

The dried sand samples were treated chemically to remove carbonates, iron oxides, and organic matter (Vos et al. 2014), and clay, silt, and other small particles attached to the sand grain surfaces were removed by wet sieving using an aperture size of $0.1 \mathrm{~mm}$ without ultrasonic vibration (Porter 1962). Quartz grains with sizes in the range of 0.1 to $1 \mathrm{~mm}$ were randomly handpicked under a stereomicroscope and placed on SEM stubs. After coating with a layer of platinum (JEOL, JFC-1600), 20 quartz grains for each sample were observed by SEM (JEOL, JSM-6610LV).

Each quartz grain was captured in a secondary electron image, and the quartz grain shape was evaluated based on the SEM images using the free software Image v1.49 (Abràmoff et al. 2004; Schneider et al. 2012). ImageJ was used to determine the shape parameters, including circularity, aspect ratio, and roundness, followed by the calculation of a roundness parameter, $R$ (Takashimizu and Iiyoshi 2016). $R$ parameter denotes circularity 
corrected by aspect ratio and shows the smoothness of grain outline.

MQS was observed with reference to the classification table of Vos et al. (2014). A total of 15 microtextures were observed (Table 1), and the number of grains possessing each microtexture was counted in every sample. A microtexture was considered to be present in a grain when the features of that microtexture were observed at more than two points on the grain or covered more than $10 \%$ of the grain surface (Higgs 1979).

\section{Results}

The grain size analysis results are shown in Table 2 and Additional file 1: Figure S1. The median particle size of samples was from $\Phi-0.2$ to 2.4. Most coastal samples contained fine to coarse sand with almost no clay or silt. Most of the samples except I-3 (Aomori) and III-4 (Chiba, fluvial sediment) were well sorted. Figure 2 and Table 2 show the mineral composition of each sample. Samples in area I (Aomori) and IV (Shizuoka) contained large amount of colored and magnetic minerals. Samples in area II (Niigata and Toyama), III (Ibaraki and Chiba), and V (Tokushima) comprised large amount of colorless minerals, rock fragments, and others.

Figure 3 shows the secondary electron images of the quartz grains. Table 2 and Additional file 2: Figure S2 show the calculated quartz roundness parameter for each sample. The standard deviation in roundness for all samples ranged from 0.03 to 0.05 , and the greatest difference in roundness was observed between I-2
(Aomori), III-3 (Toyama), and V-1 (Tokushima). I-1 to I-3, I-5, I-7 to I-9 (Aomori), II-4 (Toyama), III-1 (Ibaraki), III-3 (Chiba), and IV-1 (Shizuoka) contained grains with $\beta$-quartz shapes (Fig. 3h). The frequency of each of the 15 observed surface microtextures in each sample is shown in Fig. 4. Mechanical features such as conchoidal fractures, arcuate steps, and straight steps were common in the samples, and grains exhibiting a rounded outline and row relief (e.g., I-2 and I-8) also exhibited these mechanical features on the surface. By contrast, surface features attributed to chemical reaction (e.g., oriented etch pits and silica precipitation) were rare in all samples. Two types of MQS with large differences were observed: v-shaped percussion cracks and small holes; the frequencies of these two MQS types are shown in Table 2.

\section{Area I, Aomori}

Moving along the coastline, the median grain diameter decreased from $\Phi 0.8$ to 2.4 from I-1 to I-6 (Table 2). I-3 contained coarse particles and exhibited poor sorting (Additional file 1: Figure S1). The mineral composition differed greatly between samples; the proportion of colored minerals and magnetic minerals increased in the southern area from $16 \%$ (I-1) to $86 \%$ (I-6) and from $10 \%$ (I-7) to 91\% (I-9) (Fig. 2). Most observed colored minerals such as augite and hypersthene exhibited euhedral crystal shapes. The proportions of colorless minerals and rock fragments increased in the northern area. All nine samples in area I contained rounded grain

Table 1 Observed microtextures and their morphological features. C: chemical features, O: original features, M: mechanical features

\begin{tabular}{|c|c|c|c|c|c|}
\hline No. & Microtexture & Morphological feature & Type & Image (Fig. 3) & Reference \\
\hline 1 & Crystal overgrowth & $\begin{array}{l}\text { Thick layers of subhedral to euhedral mineral } \\
\text { precipitations }\end{array}$ & C & j & Pittman 1972; Marzolf 1976 \\
\hline 2 & Silica precipitation & Thin layer or droplets of silica precipitation & C & k & Le Ribault 1977; Higgs 1979 \\
\hline 3 & Oriented etch pits & Regular and oriented depressions & C & 1 & Amelinckx 1964; Margolis 1968, \\
\hline 4 & Solution pits & Regular and circular holes & C & $\mathrm{m}$ & Higgs 1979 \\
\hline 5 & Small holes & Small remnants of small liquid or gas inclusion & $\mathrm{O}$ & $\mathrm{n}, \mathrm{o}$ & Le Ribault 1977; Higgs 1979 \\
\hline 6 & Large holes & Large remnants of large liquid inclusion & O & $\mathrm{p}$ & - \\
\hline 7 & Upturned plates & Jagged outline and irregular in height & M & q & $\begin{array}{l}\text { Margolis and Krinsley 1974; Krinsley } \\
\text { et al. } 1976\end{array}$ \\
\hline 8 & Flat cleavage face & $\begin{array}{l}\text { Breakage patterns parallel to the quartz cleavage } \\
\text { planes }\end{array}$ & M & $c, e, r$ & Krinsley and Doornkamp 1973 \\
\hline 9 & V-shaped percussion cracks & $\begin{array}{l}\text { Usually triangular shaped depressions with an } \\
\text { average depth of } 0.1 \mu \mathrm{m}\end{array}$ & M & $g, s$ & Higgs 1979 \\
\hline 10 & Crescentic percussion marks & Cone-shaped fractures & $M$ & $t$ & Campbell 1963; Le Ribault 1977 \\
\hline 11 & Small conchoidal fracture & Shell-like breakage patterns $(<10 \mu \mathrm{m})$ & M & u & Krinsley and Doornkamp 1973 \\
\hline 12 & Medium conchoidal fracture & 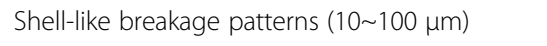 & M & $\mathrm{u}$ & Krinsley and Doornkamp 1973 \\
\hline 13 & Large conchoidal fracture & Shell-like breakage patterns $(100 \mu \mathrm{m}<)$ & M & v & Krinsley and Doornkamp 1973 \\
\hline 14 & Arcuate steps & Arcuate and successive step-like features & M & $\mathrm{o}, \mathrm{u}$ & Cardona et al. 1997 \\
\hline 15 & Straight steps & Straight and successive step-like features & M & $\mathrm{O}$ & Cardona et al. 1997 \\
\hline
\end{tabular}


Table 2 Results of grain size distribution, mineral composition ( $n>500)$, roundness of quartz, and frequency of two characteristics microtextures. Italic characters show $>0.75$ (roundness) and $>50 \%$ (frequency of v-shaped percussion cracks and small holes)

\begin{tabular}{|c|c|c|c|c|c|}
\hline Sample & Median diameters $(\Phi)$ & Dominant mineral composition group & Roundness & V-shaped percussion cracks (\%) & Small holes $(\%$ \\
\hline $\mid-1$ & 0.8 & $\mathrm{CL}$ & 0.79 & 100 & 5 \\
\hline $1-2$ & 2.0 & C & 0.80 & 90 & 5 \\
\hline $1-3$ & 1.0 & C & 0.80 & 80 & 10 \\
\hline $\mid-4$ & 1.3 & C & 0.79 & 85 & 20 \\
\hline $1-5$ & 2.1 & M & 0.77 & 65 & 5 \\
\hline $1-6$ & 2.4 & M & 0.77 & 85 & 0 \\
\hline $1-7$ & 1.2 & $\mathrm{R}, \mathrm{CL}$ & 0.77 & 75 & 10 \\
\hline $1-8$ & 0.4 & $\mathrm{R}, \mathrm{CL}$ & 0.79 & 90 & 5 \\
\hline $1-9$ & 2.0 & $M, C$ & 0.79 & 90 & 10 \\
\hline$\|-1$ & 1.7 & $\mathrm{R}, \mathrm{CL}$ & 0.72 & 15 & 35 \\
\hline$\|-2$ & 1.1 & $\mathrm{R}, \mathrm{CL}$ & 0.74 & 30 & 70 \\
\hline II-3 & -0.2 & $\mathrm{CL}$ & 0.75 & 25 & 95 \\
\hline$\|-4$ & 1.3 & $\mathrm{CL}$ & 0.73 & 70 & 80 \\
\hline |||-1 & 2.0 & $\mathrm{CL}$ & 0.76 & 95 & 25 \\
\hline|| $\mid-2$ & 2.3 & $\mathrm{CL}$ & 0.76 & 55 & 15 \\
\hline|| $\mid-3$ & 0.2 & $\mathrm{CL}$ & 0.80 & 95 & 0 \\
\hline|| $\mid-4^{a}$ & 1.3 & - & 0.79 & 85 & 10 \\
\hline IV-1 & 1.3 & $\mathrm{R}$ & 0.78 & 80 & 5 \\
\hline$V-1$ & 1.7 & $R$ & 0.71 & 30 & 80 \\
\hline
\end{tabular}

${ }^{a}$ Means fluvial sediments

Italic characters showing over $50 \%$

outlines $(R>0.75$, Table 2$)$. The surfaces of all samples in this area exhibited a high frequency of v-shaped percussion cracks $(>60 \%)$, medium conchoidal fractures $(>45 \%)$, and straight steps $(>45 \%)$, whereas small holes were rare $(<20 \%)$ (Fig. 4$)$.

\section{Area II, Niigata and Toyama}

Moving along the coastline, the median grain diameter increased from $\Phi 1.7$ to -0.2 from II-1 to II-3 (Table 2). On the basis of the mineral composition analysis, colorless minerals, rock fragments, and

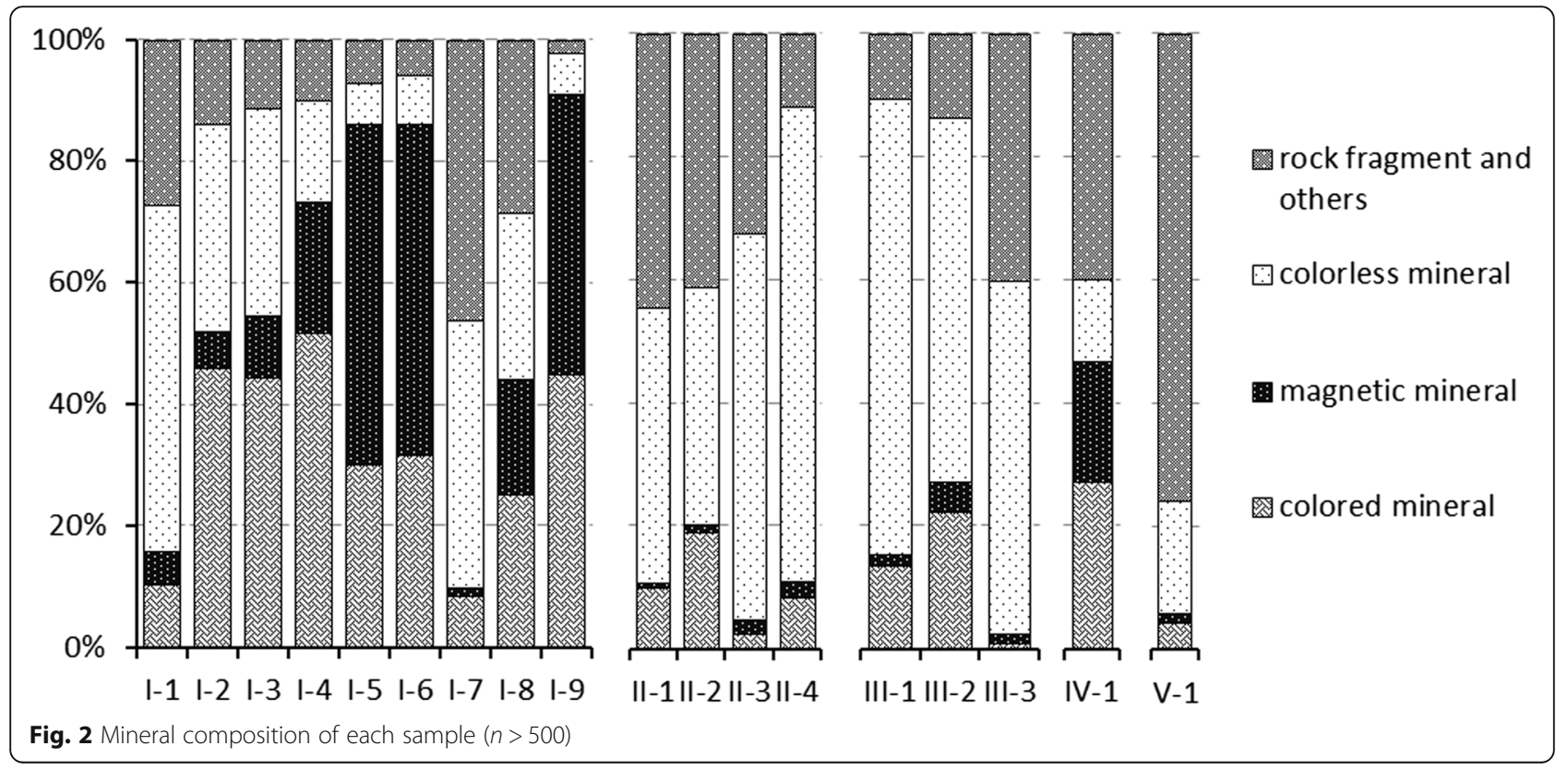



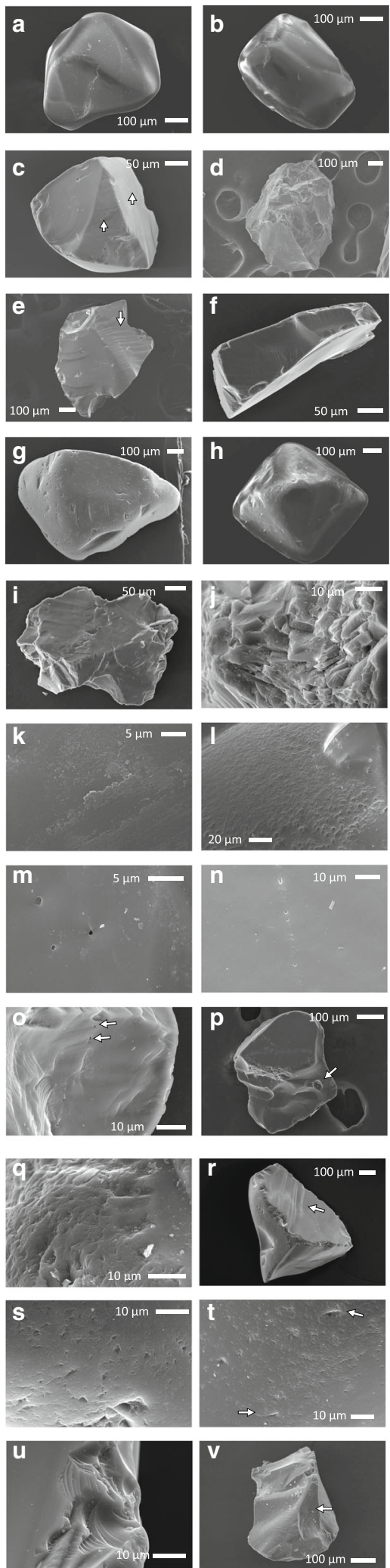

Fig. 3 SEM images. a Quartz grain of sample $1-1$ with rounded outline and low relief. b Quartz grain of sample I-4 with rounded outline and low relief. c Quartz grain of sample 1-7 with flat cleavage face (arrows). d Quartz grain of sample II-2 with angular outline and high relief. e Quartz grain of sample II-4 with flat cleavage face (arrow). f Quartz grain of sample III-2 with elongated grain shape. $\mathbf{g}$ Quartz grain of sample III-3 with rounded outline and many $\mathrm{v}$ shaped percussion cracks. $\mathbf{h}$ Quartz grain of sample IV-1 with $\beta$ quartz shape. i Quartz grain of sample V-1 with angular outline. j Crystal Overgrowth in sample 1-8. k Silica precipitation in sample I8. I Oriented etch pits in sample III-3. $\mathbf{m}$ Solution pits in sample I-6. $\mathbf{n}$ Small holes in sample II-3. o Arcuate and straight steps with small holes (arrows) in sample III-2. p Large holes (arrow) in sample I-1. q Upturned plates in sample IV-1. $\mathbf{r}$ Flat cleavage face (arrow) in sample 1-7. s V-shaped percussion cracks in sample 1-9. t Crescentic percussion marks (arrows) in sample 1-8. u Small $(<10 \mu \mathrm{m})$ and medium (10-100 $\mu \mathrm{m})$ conchoidal fractures with arcuate steps in sample 1-5. v Large (>100 $\mu \mathrm{m})$ conchoidal fracture (arrow) in sample 1-6

others were dominant (Fig. 2, Table 2). The proportion of colorless minerals increased in the western part of area II from 45\% (II-1) to 77\% (II-4). Quartz roundness was less than 0.75 , and the grain outlines were more angular than those in the other areas (Table 2). A high frequency of $\mathrm{v}$-shaped percussion cracks (70\%) was observed in sample II-4, and all samples, except II-1, exhibited high frequencies of small holes (> 70\%) (Table 2).

\section{Area III, Ibaraki and Chiba}

Although III-2 (Ibaraki) and III-3 (Chiba) were collected from sites separated by only $\sim 6 \mathrm{~km}$, their median diameters were markedly different (Table 2). Large amounts of colorless minerals, rock fragments, and others were observed in all three samples from area III (Fig. 2, Table 2). III-3 contained highly rounded quartz grains (Table 2). V-shaped percussion cracks were observed on the grain surfaces in all samples, whereas small holes were rare $(<30 \%)$ (Table 2). The number of large conchoidal fractures exceeded the number of small conchoidal fractures in III-3 (Fig. 4).

\section{Area IV, Shizuoka}

The median grain diameter of IV-1 was $\Phi 1.3$ (Table 2). As in area I, colored and magnetic mineral groups were common $(47 \%)$ in area IV (Fig. 2). The grains exhibited rounded outlines (Table 2). Medium conchoidal fractures and $\mathrm{v}$-shaped percussion cracks were abundant on the grain surfaces (80\%), whereas features related to chemical reactions were sparse. Small holes on the grain surfaces were also rare (Table 2). 


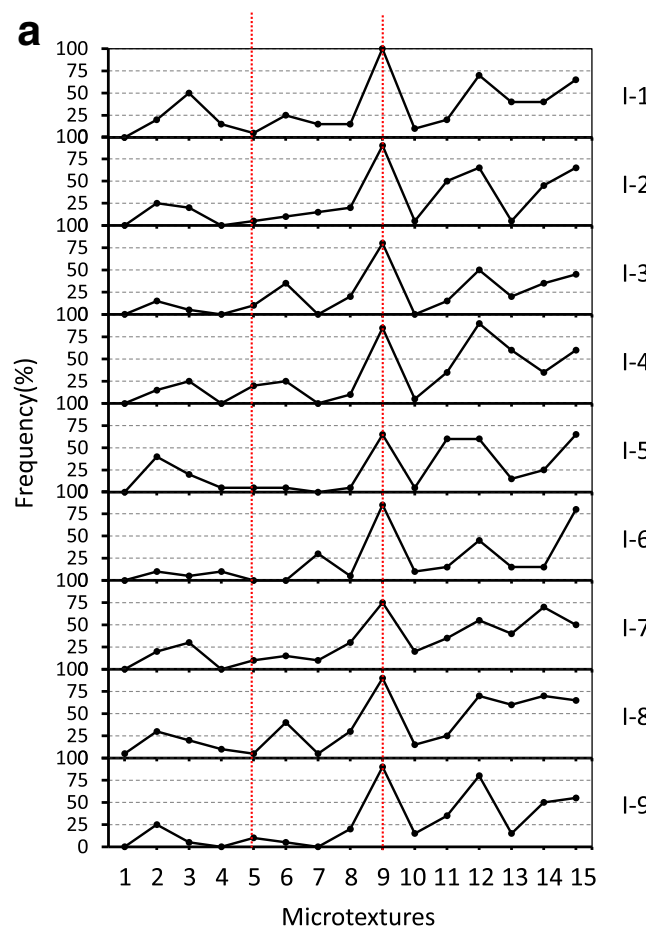

b

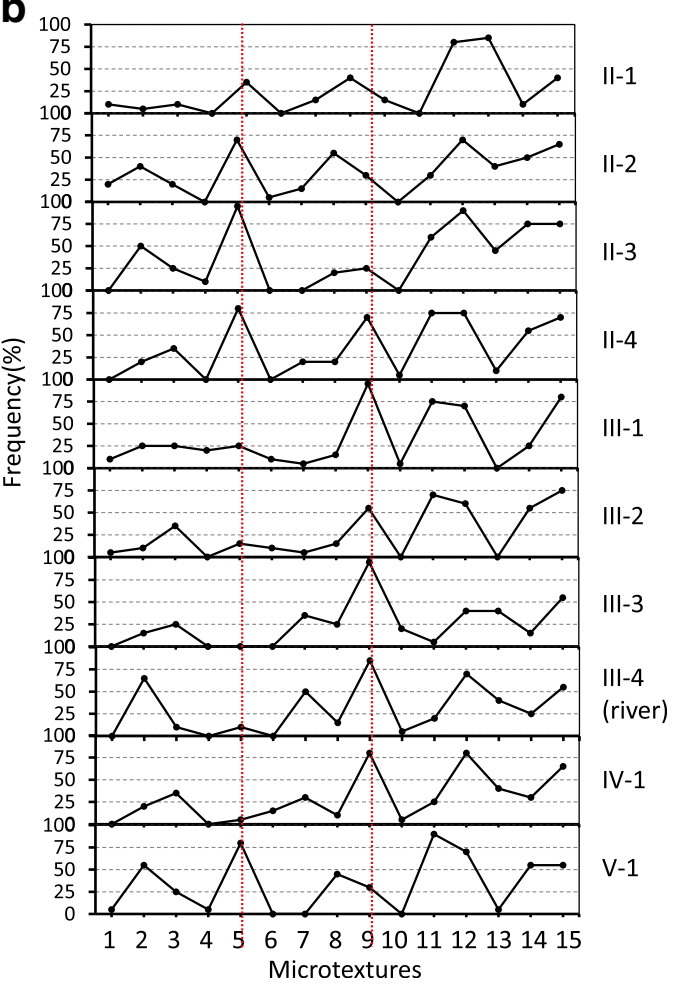

Fig. 4 Frequency of each microtexture on the quartz grain surfaces of each sample $(n=20)$ : $\mathbf{a}$ area I and $\mathbf{b}$ areas $\|-V$. The microtextures are defined as follows. 1 Crystal overgrowth; 2 silica precipitation; 3 oriented etch pits; 4 solution pits; 5 small holes; 6 large holes; 7 upturned plates; 8 flat cleavage face; 9 V-shaped percussion cracks; 10 crescentic percussion marks; 11 small conchoidal fracture $(<10 \mu \mathrm{m}) ; 12$ medium conchoidal fracture (10-100 $\mu \mathrm{m}) ; 13$ large conchoidal fracture (> $100 \mu \mathrm{m}) ; 14$ arcuate steps; 15 straight steps

\section{Area V, Tokushima}

V-1 had a median diameter of $\Phi 1.7$ (Table 2) and a high proportion of rock fragments (>70\%), most of which were green schist (Table 2). The quartz grains exhibited spatulate shapes and had the lowest roundness among all areas (Table 2). The grain surfaces in $\mathrm{V}$-1 were characterized by sparse v-shaped percussion cracks (30\%), abundant small holes (80\%), and abundant small and medium conchoidal fractures (>70\%) (Fig. 4, Table 2). The existing v-shaped percussion cracks were only partially observed and existed mainly at the grain edges, and the area of surface coverage was low.

\section{Discussion}

\section{Grain size and mineral composition}

Grain size and mineral composition differed markedly between sampling areas. Thus, the analyses can be used to estimate sediment provenance in some areas. In area I (Aomori), grain size and mineral composition showed distinct trends with location along the coastline (Fig. 2, Table 2). Mineral composition trend is considered to be attributed by the presence of volcano. This area is covered with terrace deposit and volcanic rocks (Yoshida 2017). Grains with $\beta$-quartz shapes were contained in samples except for I-4 and I-6. Quartz occurred as euhedral phenocrysts in such as rapidly cooled extrusive and hypabyssal rocks (Gribble and Hall 1992). By microscopic observation, samples taken from the southern area contained abundant magnetic minerals and colored minerals such as augite and hypersthene, which is also contained in tephra of Towada volcano (Hayakawa 1985; Machida and Arai 2003). Although a more detailed investigation is needed to clearly identify the provenance of colored and magnetic minerals in area I, coastal sand in the southern part of area I were more strongly influenced by pyroclastic deposits of volcano. The change in the proportion of heavy minerals along the coastline may indicate the direction of coastal drift. The direction of sand drift in this area is north near site I-3 to I-6, no direction near site I-2 and south near site I-1 (Sato et al. 1972). However, in this study, the median diameter of the samples was larger in the northern part of area I 
than in the southern part. Thus, sand drift does not likely explain the observed differences in mineral composition in area I. So what caused variation in grain size distributions? It appears that many factors relate to grain-size trend such as offshore bathymetry, wave energy, sediment composition, and sand grain size in parent rock. It is hard to decide the main cause by the result of mineral composition and quartz morphology, so other data is needed to explain the grain-size trend in this area.

In area III (Ibaraki and Chiba), although the sampling locations of III-2 (Ibaraki) and III-3 (Chiba) were close to one another (6 km apart), these samples had completely different grain sizes (Table 2). For comparison, the median diameter of the fluvial sediments III-4, $8 \mathrm{~km}$ upstream of the mouth of the Tone River, was larger than III-2 (Table 2). Sato et al. (2000) and Uda et al. (2007a) reported that beach sand at site III-2 was supplied from the Tone River. Conversely, grain size at III-3 was larger than fluvial sediments III-4 and the coastal line shows a natural pocket beach. In consideration of the grain size and geomorphological setting, III-2 was likely derived from a fluvial supply, whereas the origin of III-3 was not fluvial. That is, III-2 and III-3 originated from different sources.

In area $\mathrm{V}$ (Tokushima), the types of rock fragments found in the samples also provide clues as to the origins of the quartz grains. V-1 contained a large number of rock fragments, most of which were identified as green schist (Table 2). Green schist covers a wide area of the drainage basin of Yoshino River, which flows near site V-1 (Isomi 1959; Makimoto et al. 1995; Matsuura et al. 2002). This suggests that sediments, including fragments of green schist, were transported from the upstream area of Yoshino River and deposited on the beach.

\section{Quartz shape}

In the classification table of Vos (Vos et al. 2014), grain outline is divided into three groups based on appearance: angular, subangular, and rounded. We attempted to quantify grain outline in this study. Quartz outline was evaluated based on a new roundness parameter calculated in ImageJ (Takashimizu and Iiyoshi 2016). This parameter accurately reflects the quartz outline observed in SEM images and provides a consistent interpretation of sediment supply and parent rock, as detailed below.

The samples from areas II (Niigata and Toyama) and $\mathrm{V}$ (Tokushima) exhibited roundness values under 0.75 and relatively angular grain outlines (Fig. 3d, e, i) compared to the samples from the other areas. In area II (Niigata and Toyama), where steep rivers flow, grains are thought to be transported in high-energy subaqueous environments without edge rounding (Helland and Holmes 1997), resulting in angular outlines. V-1 (Tokushima) was also influenced by river supply (Yoshino River) and showed the lowest roundness among all samples. Pyökäri (1997) also stated that roundness of sediment grains at beach discharged from river was poor. Another reason for $\mathrm{V}-1$ showing angular outline was the parent rock. V-1 is likely derived from green schist, containing irregular shaped oblate quartz (Nishikawa et al. 1994). Thus, the angular quartz outline of V-1 may have resulted from regional metamorphism.

On the other hand, I-1 through I-9 (Aomori), III-3 (Chiba), and IV-1 (Shizuoka) contained relatively rounded quartz grains $(R>0.75)$ partly because the corresponding sediments were not influenced by a large river and were subjected to long periods in coastal environments. Thus, the rounded grain outlines likely resulted from long transport distance and time or large amount of recycled sediments (Madhavaraju et al. 2009). Alternatively, the rounded grain outline may reflect the original grain shape generated by the parent rock. As indicated in previous studies, grain outline is related to both the transportation process and the original grain shape of the source rock (Goudie and Watson 1981; Kleesment 2009; Costa et al. 2013). In this study, the geological settings of sampling area containing rounded quartz grain are volcanic rock or ash. The samples in area I (Aomori) were influenced by the volcano, and most of area IV (Shizuoka) is covered with volcanic sediment (Hayakawa 1985; Machida and Arai 2003; Sugiyama et al. 2010; Takeuchi et al. 2015). III-3 (Chiba) contains grains with $\beta$-quartz shapes which are thought to be influenced by volcanic rock (Gribble and Hall 1992). The rounded quartz grains observed in this study may be attributed to the original shapes of the volcanic rocks, along with the depositional environment.

\section{Quartz surface features}

Quartz grains from coastal environments are characterized by subangular to rounded outlines, silica precipitation, oriented etch pits, and v-shaped percussion cracks (Krinsley and Doornkamp 1973; Higgs 1979). In this study, features produced by pressure or powerful impacts on grains such as flat cleavage face, small to large conchoidal fractures, arcuate steps, and straight steps were common in all samples, whereas features produced by chemical reaction were sparse. This microtextural trend corresponded to the neither nearshore nor dune but beach sample in Costa's model, namely fresh surfaces and percussion marks are dominant features (Costa et al. 2012). Moreover, Margolis (1968) reported that sand grains from beaches with low wave activity (mean wave height, $0-0.1 \mathrm{~m}$ ) exhibit features produced by 
chemical reaction, whereas grains from high-energy beaches (mean wave height, $0.5 \mathrm{~m}<$ ) show mechanical features. Mean wave heights of studied areas in 2016 were approximately $0.7 \mathrm{~m}$ for area I Aomori; $0.3-0.6 \mathrm{~m}$ for area II, Niigata and Toyama; $0.8 \mathrm{~m}$ for area III, Ibaraki and Chiba; $0.6 \mathrm{~m}$ for area IV, Shizuoka; and $0.3 \mathrm{~m}$ for area V, Tokushima (Nationwide Ocean Wave information network for Ports and HArbourS, NOWPHAS 2016). This suggests that all 18 samples in this study were subjected to moderate to high energy beach conditions.

In the course of this study, 15 types of surface microtextures were observed, with large differences in microtexture frequency observed between two of them: v-shaped percussion cracks and small holes (Fig. 4, Table 2). Conchoidal fractures (Nos.11-13) and steps (Nos.14-15) could not be used because they were very common among all the samples. The size of conchoidal fractures may not be related to the sedimentary history but were related to the grain size (Fig. 4, Table 2). Other microtextures except $\mathrm{v}$-shaped percussion cracks and small holes could not be used to interpret the sedimentary history clearly because they were rare frequency or no definitive differences in all samples (Fig. 4). Therefore, two surface features are considered to be characteristic features that reflect the diversity of the beach sand samples, as discussed in detail below.

\section{V-shaped percussion cracks}

In the subaqueous environment, $\mathrm{v}$-shaped percussion cracks are produced by grain-to-grain collisions (Krinsley and Doornkamp 1973; Margolis and Krinsley 1974; Mahaney and Kalm 2000). In this study, the observed differences in the frequency of this feature are thought to show the transportation process. No major river mouth is located near the sampling sites in areas I (Aomori) and IV (Shizuoka), where the grains have many percussion cracks; by contrast, sites II-1 through II-3 (Niigata and Toyama) and V-1 (Tokushima), in which the grains exhibited few percussion cracks, were located near the mouths of rivers. This correlation is discussed below in terms of the geomorphological settings of Japan. Compared to rivers in other parts of the world, most rivers in Japan are short and steep, and the sediment yields from steep watersheds are much larger than those from less steep watersheds (Ohmori 1983; Oguchi et al. 2001). Fluvial sediments in Japan are thought to have short transport times in the subaqueous environment before being deposited on the coast. II-1 to II-3 and V-1 did not have quartz grains with marine characteristics (i.e., rounded outlines, medium relief, silica precipitation, and v-shaped percussion cracks) (Krinsley and Doornkamp 1973; Higgs 1979; Vos et al. 2014). These samples, which were collected near a river mouth, are thought to have been influenced by river supply. The sediments corresponding to these samples were only located on the coast for a short time as a result of the large amount of sediment supply from rivers $(0.9 \sim 6.2 \times$ $10^{6} \mathrm{~m}^{3} /$ year, Udo et al. 2016); thus, there was no sufficient time to produce percussion cracks on their grain surfaces in the coastal environment. This interpretation is consistent with the findings of Margolis and Kennett (1971), who found that v-shaped percussion cracks generally occur on less than $50 \%$ of grains of fluvial origin and on more than $50 \%$ of grains from high-energy beaches.

However, grains from some sampling sites near a river mouth had abundant percussion cracks. For example, III-3 (Chiba), which was collected from approximately $4 \mathrm{~km}$ away from the mouth of the Tone River, had abundant percussion cracks (95\%; Table 2) and exhibited marine characteristics. III-3 was not supplied from the Tone River as described in discussion of grain size and mineral composition section. The coastline at site III-3 shows a natural pocket beach, and the grains may have been subjected to extended periods in the coastal environment, resulting in the percussion cracks. The environment of site III-1 resembles to that of site III-3. Site III-1 (Ibaraki) is approximately $6 \mathrm{~km}$ away from the mouth of the Naka River. However, considering the southward sand drift at river mouth (Uda et al. 2007b) and coastline of pocket beach, III-1 was not influenced by river supply and showed abundant percussion cracks (95\%: Table 2) like III-3.

In conclusion, in this study, the differences in the frequency of $\mathrm{v}$-shaped percussion cracks on quartz grain surfaces observed between the samples are related to transportation process (i.e., whether the sediments at the sampling sites were primarily influenced by fluvial supply or not).

\section{Small and large holes}

In this study, the small holes on the quartz grain surfaces, which were sometimes aligned on a fresh plane with a diameter of approximately $1 \mu \mathrm{m}$, were derived from the remnants of small inclusions in the grain (Le Ribault 1977; Higgs 1979). Small volumes of liquid or gas inclusions within a crystal were frequently observed by optical microscopy in grains with small holes on the surface. The sizes of the small holes observed by SEM agreed with those determined under optical microscope $(\sim 5 \mu \mathrm{m})$.

The small holes observed in this study were derived from the remnants of small inclusions rather than by mechanical forces, like the v-shaped percussion cracks. Inclusions are trapped during the growth of the host crystal or during the healing of fractures in the host crystal after crystallization. The presence of inclusions 
indicates the presence of fluid during the initial crystal growth or subsequent fracture healing (Roedder 2003). Many small inclusions are generated when the crystal grows rapidly (Sorby 1858; Takenouchi 1975). Inclusion was used to get information of geology and geochemistry, for example, the search for ore deposits (Roedder 2003). Considering the mechanisms of inclusion trapping, the frequency of small holes on the quartz grain surface may provide information about the geologic source of the quartz. All nine samples collected in area I (Aomori) had low frequencies of small holes $(<20 \%)$, indicating that the quartz grains in these samples may be derived from similar geological provenances. In area II (Niigata and Toyama), II-1 showed a lower frequency of small holes (Table 2) than the other samples (II-2 through II-4). This may indicate that the sediments at site II-1, which is located on the eastern side of the ISTL, have a different geological provenance from the sediments at the other sampling sites.

Large holes with diameter $>10 \mu \mathrm{m}$ also seemed to be derived from large inclusions (Fig. 3p). Large inclusions are generated when the crystal grows slowly under high temperature (Sorby 1858; Takenouchi 1975). On the basis of the stereomicroscopic observations, the samples collected in areas I (Aomori), III (Ibaraki and Chiba), and IV (Shizuoka) contained some grains with large clear or gray fluid inclusions. Thus, the frequencies of the large holes also have the potential to provide information about geological provenance; however, the differences in the frequencies of large holes observed in this study ( $0 \%$ to $40 \%$ ) were lower than those of small holes. Inclusion size is thought to be related to inclusion abundance; inclusions with size $<10 \mu \mathrm{m}$ are one or two orders of magnitude more abundant than those with size $>10 \mu \mathrm{m}$ (Roedder 2003). Thus, in MQS analysis, the more frequently observed small holes may be more helpful for the study of provenance compared to large holes because of the number of inclusions remnant on surface.

\section{Overall discussion}

In this study, we attempted to apply quartz surface analysis in combination with quartz shape analysis to estimate sediment provenance. Grain size and mineral composition were also analyzed. MQS analysis revealed that the beach sands in Japan had a morphological diversity of quartz as previous study, i.e., (1) few v-shaped percussion cracks were observed from fluvial supply beach (Margolis and Kennett 1971), and (2) features produced by chemical reaction were sparse owing to the high-energy of beaches (Margolis 1968). In the studied areas, two characteristic features reflected the sedimentary history: (1) small holes derived from the remnants of small inclusions in the grains showed parent rock and (2) v-shaped percussion cracks produced by grain-to-grain collisions in the aqueous environment showed transportation process. Figure 5 presents a conceptual model that explains relation between the quartz morphological features and the sampling site. In area III (Ibaraki and Chiba), although III-2 (Ibaraki) and III-3 (Chiba) were collected from sites located close to one another, their MQS were completely different because of a difference in sediment provenance. By contrast, the MQS of samples collected in area I (Aomori) were similar because the geologic source and depositional environment of the sampling sites are similar. These findings indicate that quartz surface textures depend on the geologic source, transportation process, and depositional environment, namely the geomorphological and geological settings.

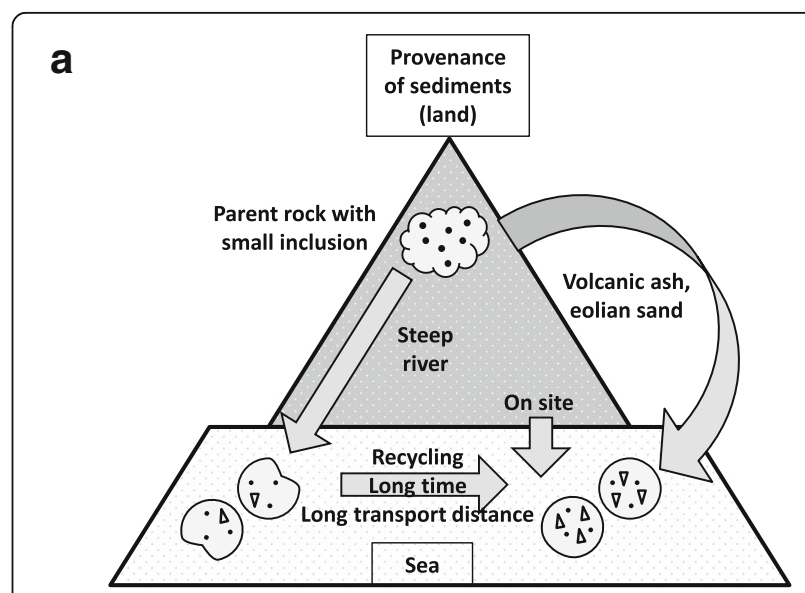

Rare V-shaped percussion cracks and abundant small holes (II-2, II-3, V-1)
Abundant V-shaped percussion cracks and abundant small holes (II-4)

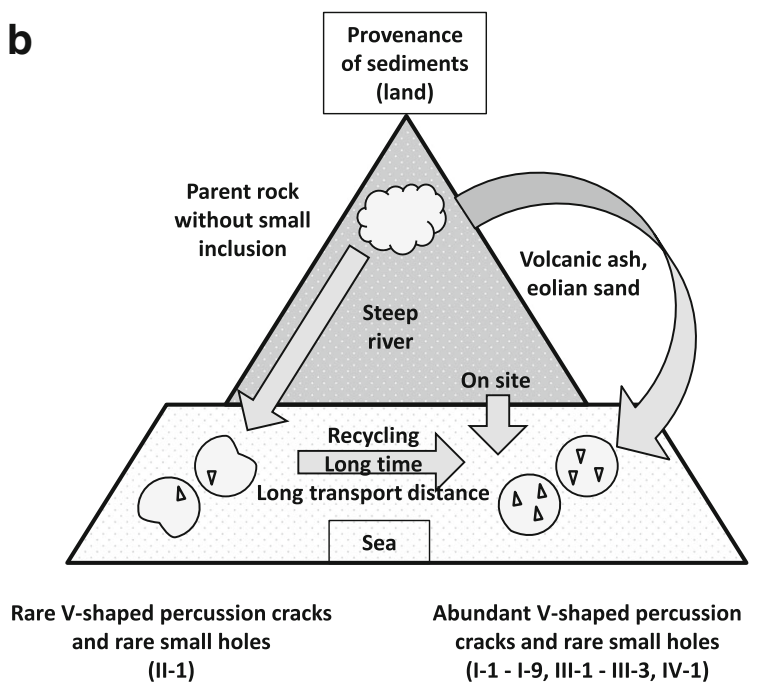

Fig. 5 Model depicting the quartz grain history from production to deposition and the diversity of grain surface microtexture: $\mathbf{a}$ grains with abundant small inclusions and $\mathbf{b}$ grains with few small inclusions 
The different point herein from the previous studies is the importance of unweathered grain shape. In previous studies, analyses of quartz surface morphology typically assumed that quartz grains originated from granite rock or glacial sediment and that unweathered quartz grains showed angular outlines with many conchoidal fractures on their surfaces (Krinsley and Doornkamp 1973). However, in this study, quartz grains that originated from volcanic rock showed rounded outlines in area I (Aomori) and IV (Shizuoka) and grains from green schist showed angular outline in area V (Tokushima). This suggests that the parent rock has a strong influence on quartz shape, along with the transportation process and depositional environment. Some reports indicate that grain outline is related to the original shape in the source rock (Goudie and Watson 1981; Kleesment 2009; Costa et al. 2013). Therefore, it is necessary to investigate the relationship between parent rock and unweathered shape and surface texture of quartz to better understand quartz provenance, especially in locations with complex geological settings like Japan.

\section{Conclusions}

We analyzed the grain size and mineral composition of sediment samples, along with the microtextures and shapes of quartz grains, from various beach sands in Japan. It is revealed that the morphological diversity of quartz grains can be observed at beach. The relationship between the morphological features of quartz and the geomorphological and/or geological settings of sediment deposition was based on previous studies. A further important point is to clarify the relation between unweathered quartz grain and parent rock. Even in areas with complex geologic and geomorphological settings such as Japan, our data first suggested that MQS analysis combined with other analyses can provide useful information for the study of provenance. The MQS analysis has the potential to provide information regarding the geologic provenance as well as the geomorphological setting in other depositional environments in Japan.

\section{Additional file}

Additional file 1: Figure S1. Grain size distribution for each sample. (JPG $91 \mathrm{~kb}$ )

Additional file 2: Figure S2. Roundness parameter of quartz grains in each sample. Larger $\mathrm{R}$ value means more rounded grains. $n=20$ and mean \pm SD. (JPG $73 \mathrm{~kb}$ )

\section{Abbreviations}

ISTL: Itoigawa-Shizuoka Tectonic Line; MQS: Microtexture of a quartz surface; SEM: Scanning electron microscopy

\section{Acknowledgements}

We thank the students at the University of Tokyo for assistance in sampling at areas II (Niigata and Toyama) and III (Ibaraki and Chiba) along with technical support during grain size analysis. The authors would like to thank Mr. Kento Kumisaka and Mr. Masaaki Nakashima for help in sampling, observation, and discussion.

\section{Authors' contributions}

$\mathrm{HI}, \mathrm{RS}$, and TS proposed the topic, conceived and designed the study. $\mathrm{HI}$ conducted the experimental study and analyzed the data. RS and TS helped in their interpretation. $\mathrm{HI}$ collaborated with the corresponding author in the drafting of manuscript. All authors have read and approved the final manuscript.

\section{Funding}

This work was supported by JSPS KAKENHI Grant Number JP16K16351.

\section{Availability of data and materials}

The datasets used and analyzed during the current study are available from the corresponding author on reasonable request.

\section{Competing interests}

The authors declare that they have no competing interest.

\section{Publisher's Note}

Springer Nature remains neutral with regard to jurisdictional claims in published maps and institutional affiliations.

Received: 20 November 2018 Accepted: 6 May 2019

Published online: 11 June 2019

\section{References}

Abràmoff MD, Magalhãe PJ, Ram SJ (2004) Image processing with ImageJ. Biophoton Int 11:36-42

Amelinckx S (1964) The direct observation of dislocations. Academic, New York Bellanova P, Bahlburg H, Nentwig V, Spiske M (2016) Microtextural analysis of quartz grains of tsunami and non-tsunami deposits-a case study from Tirúa (Chile). Sediment Geol 343:72-84

Campbell DH (1963) Percussion marks on quartz grains. J Sediment Res 33:855859

Cardona JPM, Gutiérrez Mas JM, Bellón AS, López-Aguayo F, Caballero MA (1997) Provenance of multicycle quartz arenites of Pliocene age at Arcos, southwestern Spain. Sediment Geol 112:251-261

Costa PJM, Andrade C, Dawson AG, Mahaney WC, Freitas MC, Paris R, Taborda R (2012) Microtextural characteristics of quartz grains transported and deposited by tsunamis and storms. Sediment Geol 275-276:55-69

Costa PJM, Andrade C, Mahaney WC, Marques da Silva F, Freire P, Freitas MC, Janardo C, Oliveira MA, Silva Tiago A, Lopes V (2013) Aeolian microtextures in silica spheres induced in a wind tunnel experiment: comparison with aeolian quartz. Geomorphology 180-181:120-129

Costa PJM, Gelfenbaum G, Dawson S, La Selle S, Milne F, Cascalho J, Lira CP. Andrade C, Freitas MC, Jaffe B (2018) The application of microtextural and heavy mineral analysis to discriminate between storm and tsunami deposits. In: Scourse EM, Chapman NA, Tappin DR, Wallis SR (eds) Tsunamis: geology, hazards and risks, vol 456. Geological Society, London, pp 167-190

Fukuda H (1939) The flow volume of the Hime River in Niigata prefecture in the snowmelt season (Title_in_Japanese). J Agric Eng Soc Jpn 11(1):37-42

Fukuda $\mathrm{H}$, Sekiguchi A (1940) The flow volume of five rivers in snowmelt season (Title_in_Japanese). J Agric Eng Soc Jpn 12(4):253-263

Geological Survey of Japan, National Institute of Advanced Industrial Science and Technology (2015) Seamless digital geological map of Japan 1: 200,000 https://gbank.gsj.jp/seamless/seamless2015/2d/. Accessed 10 Sep 2018.

Geospational Information Authority of Japan (2013) GSI Maps. https://maps.gsi. go.jp. Accessed 10 Sep 2018.

Goldich SS (1938) A study in rock-weathering. J Geol 46:17-58

Goudie ASW, Watson A (1981) The shape of desert sand dune grains. J Arid Environ 4:185-190

Gribble CD, Hall AJ (1992) Optical mineralogy: principles and practice. UCL Press, London

Handa K, Chinaka H, Ishikawa K, Miyazawa K (2013) A monitoring for sediment movement in the Hime River basin (Title in Japanese). J Jpn Soc Erosion Control Eng 66:01-02

Harayama S, Takizawa F, Kato H, Komazawa M, Hiroshima T, Sudo S (1996) Geological map of Japan 1:200,000. Geological Survey of Japan, Toyama 
Hayakawa Y (1985) Pyroclastic geology of Towada volcano. Bull Earthq Res Inst Univ Tokyo 60:507-592

Helland PE, Holmes MA (1997) Surface textural analysis of quartz sand grains from ODP site 918 off the southeast coast of Greenland suggests glaciation of southern Greenland at 11 ma. Palaeogeogr Palaeoclimatol Palaeoecol 135: 109-121

Higgs R (1979) Quartz-grain surface features of Mesozoic-Cenozoic sands from the Labrador and western Greenland continental margins. J Sediment Res 49:599-610

Ishii A, Hagiya H, Watanabe K (2009) Estimation of sediment transport based on mineral and chemical composition of beach sand. Annu J Civ Eng Ocean 25: $1107-1111$

Isomi H (1959) Geological map of Japan 1:200,000. Geological Survey of Japan, Kochi

Kamada K, Hata M, Kubo K, Sakamoto T (1991) Geological map of Japan 1: 200,000. Geological Survey of Japan, Hachinohe

Kanaori Y, Miyakoshi K, Kakuta T, Satake Y (1980) Dating fault activity by surface textures of quartz grains from fault gouges. Eng Geol 16:243-262

Kanaori Y, Tanaka K, Miyakoshi K (1985) Further studies on the use of quartz grains from fault gouges to establish the age of faulting. Eng Geol 21:175-194

Kanaori Y, Yairi K, Ishida T (1991) Grain boundary microcracking of granitic rocks from the northeastern region of the Atotsugawa fault, Central Japan: SEM backscattered electron images. Eng Geol 30:221-235

Kleesment A (2009) Roundness and surface features of quartz grains in middle Devonian deposits of the East Baltic and their palaeogeographical implications. Est J Earth Sci 58:71-84

Krinsley DH, Doornkamp JC (1973) Atlas of quartz sand surface textures. Cambridge University Press, Cambridge, p 32

Krinsley DH, Friend PF, Klimentidis R (1976) Eolian transport textures on the surfaces of sand grains of Early Triassic age. Geol Soc Am Bull 87:130-132

Le Ribault L (1977) L'exoscopie des quartz. Editions Masson

Machida H, Arai F (2003) Atlas of tephra in and around Japan. University of Tokyo Press, Tokyo

Madhavaraju J, JCGy B, Hussain SM, Mohan SP (2009) Microtextures on quartz grains in the beach sediments of Puerto Peñasco and Bahia Kino, Gulf of California, Sonora, Mexico. Rev Mex Cienc Geol 26:367-379

Mahaney WC (2002) Atlas of sand grain surface textures and applications. Oxford University Press, Oxford

Mahaney WC, Dohm JM (2011) The 2011 Japanese 9.0 magnitude earthquake: test of a kinetic energy wave model using coastal configuration and offshore gradient of Earth and beyond. Sediment Geol 239:80-86

Mahaney WC, Kalm V (2000) Comparative scanning electron microscopy study of oriented till blocks, glacial grains and Devonian sands in Estonia and Latvia. Boreas 29:35-51

Makimoto H, Toshimatsu S, Takahashi Y, Mizuno K, Komazawa M, Shichi R (1995) Geological map of Japan 1:200,000, 2nd edn. Geological Survey of Japan, Tokushima

Margolis SV (1968) Electron microscopy of chemical solution and mechanical abrasion features on quartz sand grains. Sediment Geol 2:243-256

Margolis SV, Kennett JP (1971) Cenozoic paleoglacial history of Antarctica recorded in Subantarctic deep-sea cores. Am J Sci 271:1-36

Margolis SV, Krinsley DH (1974) Processes of formation and environmental occurrence of microfeatures on detrital quartz grains. Am J Sci 274:449-464

Marzolf JE (1976) Sand-grain frosting and quartz overgrowth examined by scanning electron microscopy; the Navajo sandstone (Jurassic (?)), Utah. J Sediment Res 46:906-912

Matsuura H, Kurimoto C, Yoshida F, Saito Y, Makimoto H, Toshimitsu S, Iwaya Tm Komazawa M, Hiroshima T (2002) Geological map of Japan 1:200,000 Geological Survey of Japan, Okayama and Marugame

Mii H, Fuji I (1970) Grain size distribution and surface texture of eolian and aqueous sand (Title_in_Japanese). J Geol Soc Jpn 76(2):87-88

Mitsui H, Ozima M, Murakami H (1979) Investigation on sediment distribution, characteristics of tidal oscillation and salinity of underground water on coastal area in Tokushima (Title_in_Japanese). Proc Jpn Conf Coast Eng 26: 633-637

Moreno T, Wallis S, Kojima T, Gibbons W (eds) (2016) The geology of Japan. The Geological Society Publishing House, Bath

Nationwide Ocean Wave information network for Ports and HArbourS, NOWPHAS (2016), Ports and Harbours Bureau, Ministry of Land, Infrastructure, Transport, and Tourism (MLIT). http://www.mlit.go.jp/kowan/nowphas/index. html, Accessed 13 Feb 2019
Newsome D, Ladd P (1999) The use of quartz grain microtextures in the study of the origin of sand terrains in Western Australia. CATENA 35:1-17

Nishikawa O, Misawa T, Ogawa S, Otsuki K (1994) Structural analysis of low grade metamorphic rocks of Sambagawa Belt in central Shikoku, Japan. J Geol Soc Jpn 100:901-914

Niwa M, Shimada K, Aoki K, Ishimaru T (2016) Microscopic features of quartz and clay particles from fault gouges and infilled fractures in granite: discriminating between active and inactive faulting. Eng Geol 210:180-196

Oguchi T, Saito K, Kadomura H, Grossman M (2001) Fluvial geomorphology and paleohydrology in Japan. Geomorphology 39:3-19

Ohmori H (1983) Characteristics of the erosion rate in the Japanese mountains from the viewpoint of climatic geomorphology. Z Geomorphol Neue Folge Suppl Band 46:1-14

Okubo M, Monodane S (1974) Electron microscopy of the geologic materials (part 1): the surface textures of quartz sand grains, Geology, Separated from the Memoirs of the Faculty of Literature and Science, Shimane University, Natural Sciences, vol 7, pp 95-100

Pittman ED (1972) Diagenesis of quartz in sandstones as revealed by scanning electron microscopy. J Sediment Petrol 42:507-519

Porter JJ (1962) Electron microscopy of sand surface texture. J Sediment Petrol 32:124-135

Pyökäri M (1997) The provenance of beach sediments on Rhodes, southeastern Greece, indicated by sediment texture, composition and roundness. Geomorphology 18:315-332

Roedder E (2003) Fluid inclusions. In: Meyers RA (ed) Encyclopedia of physical science and technology (third edition). Academic, New York

Saito H, Nakayama D, Matsuyama H (2010) Relationship between the initiation of a shallow landslide and rainfall intensity—duration thresholds in Japan. Geomorphology 118:167-175

Sakamoto T, Imai I, Sumi Y, Nozawa T, Moritani T (1967) Geological map of Japan 1:200,000. Geological Survey of Japan, Nanao and Toyama

Sato S, Kasai T, Tanaka N, Irie I (1972) Drift sand in coastal area at Lake Ogawara (Title_in_Japanese). Proc Jpn Conf Coast Eng 19:7-11

Sato S, Maeda R, Isobe M, Sekimoto T, Kasai M, Yamamoto K (2000) The mechanism of and drifts at the mouth of Tone River and sedimentary supply for Hasaki beach (Title_in_Japanese). Proc Coast Eng JSCE 47:656660

Schneider CA, Rasband WS, Eliceiri KW (2012) NIH image to ImageJ: 25 years of image analysis. Nat Methods 9(7):671-675

Sorby HC (1858) On the microscopic structure of crystals, indicating the origin of minerals and rocks. Quart J Geol Soc 14:32-37

Sudo S, Makimoto H, Hata M, Unosawa A, Takizawa F, Sakamoto T, Komazawa M, Hiroshima T (1991) Geological map of Japan 1:200,000. Geological Survey of Japan, Utsunomiya

Sugiyama Y, Mizuno K, Kano K, Muramatsu T, Matsuda T, Ishizuka O, Oikawa T, Kakada A, Arai K, Okamura Y, Sanematsu K, Takahashi M, Oyama Y, Komazawa M (2010) Geological map of Japan 1:200,000, 2nd edn. Geological Survey of Japan, Shizuoka and Omae Zaki

Takashimizu Y, liyoshi M (2016) New parameter of roundness R: circularity corrected by aspect ratio. Prog Earth Planet Sci 3:2

Takenouchi S (1975) Basic knowledge on studies of fluid inclusions minerals -1historical review, classification and formation of fluid inclusions. J Gemmol Soc Jpn 2:25-33

Takeuchi K, Kato H, Yanagisawa Y, Hiroshima T (1994) Geological map of Japan 1: 200,000. Geological Survey of Japan, Takada

Takeuchi K, Oikawa T, Saito M, Ishizuka O, Sanematsu K, Komazawa M (2015) Geological map of Japan 1:200,000, 2nd edn. Geological Survey of Japan, Yokosukka

Tsushima K (1964) Geological map of Japan 1:200,000. Geological Survey of Japan, Noheji

Uda T, Katsuyama H, Matsu-Ura T, Kumada T, Nagayama H, Oki Y (2007a) Beach changes around Hazaki fishing port next to Tone River mouth and their prediction. Proc Coast Eng JSCE 54:586-590

Uda T, Sumiya M, Nagayama H, Oki Y, Kumada T (2007b) Rapid Beach erosion caused by extraordinary waves on coast with exhausted sand source and advanced seawall. Proc Civ Eng Ocean 23:1201-1206

Udo K, Takeda Y, Yokoo Y (2016) Relationship between potential sediment supply from river to sea and beach erosion in Japan. J Jpn Soc Civ Eng Ser B2 (Coastal Engineering) 72:I_799-I_804

Unosawa A, Oka S, Sakamoto T, Komazawa M (1983) Geological map of Japan 1: 200,000. Geological Survey of Japan, Chiba 
Vos K, Vandenberghe N, Elsen J (2014) Surface textural analysis of quartz grains by scanning electron microscopy (SEM): from sample preparation to environmental interpretation. Earth-Sci Rev 128:93-104

Woronko B (2016) Frost weathering versus glacial grinding in the micromorphology of quartz sand grains: processes and geological implications. Sediment Geol 335:103-119

Yamada N, Nozawa T, Harayama S, Takizawa F, Kato H, Hiroshima T, Komazawa M (1989) Geological map of Japan 1:200,000. Geological Survey of Japan, Takayama

Yamamoto T, Takizawa F, Takahashi Y, Kubo K, Komazawa M, Hiroshima T, Sudo S (2000) Geological map of Japan 1:200,000. Geological Survey of Japan, Nikko

Yonekura N (2001) Characteristics of plains. Introduction to Japanese geomorphology, regional geomorphology of the Japanese Islands, vol 1. University of Tokyo Press, Tokyo

Yoshida T (2017) Neogene-Quaternary (Title in Japanese). In: Yoshida T (ed) Regional geology of Japan, vol 2. Tohoku Region, Asakura Publ, Tokyo, pp 329-381

Yoshioka T, Takizawa F, Takahashi M, Miyazaki K, Banno Y, Yanaghisawa Y, Takahashi Y, Kubo K, Seki Y, Komazawa M, Hiroshima T (2001) Geological Map of Japan 1:200,000, 2nd edn. Geological Survey of Japan, Mito

\section{Submit your manuscript to a SpringerOpen ${ }^{\odot}$ journal and benefit from:}

- Convenient online submission

- Rigorous peer review

- Open access: articles freely available online

- High visibility within the field

Retaining the copyright to your article

Submit your next manuscript at $\boldsymbol{\nabla}$ springeropen.com 